\title{
Primary Hyperparathyroidism: Defining the Appropriate Preoperative Imaging Algorithm
}

\author{
Elif Hindié ${ }^{1}$, Paul Schwartz ${ }^{1}$, Anca M. Avram ${ }^{2}$, Alessio Imperiale ${ }^{3}$, Frederic Sebag ${ }^{4}$, and David Taïeb ${ }^{5}$ \\ ${ }^{I}$ Department of Nuclear Medicine, University Hospitals of Bordeaux, TRAIL, University of Bordeaux, Bordeaux, France; ${ }^{2}$ Division of \\ Nuclear Medicine and Molecular Imaging, Department of Radiology, University of Michigan, Ann Arbor, Michigan; ${ }^{3}$ Nuclear Medicine \\ and Molecular Imaging, ICANS, University Hospitals of Strasbourg, University of Strasbourg, IPHC, Strasbourg, France; ${ }^{4}$ Endocrine \\ Surgery, La Timone Hospital, Aix-Marseille University, Marseille, France; and ${ }^{5}$ Nuclear Medicine, La Timone Hospital, CERIMED, \\ Aix-Marseille University, Marseille, France
}

Primary hyperparathyroidism is a common and potentially debilitating endocrine disorder for which surgery is the only curative treatment. Preoperative imaging is always recommended, even in cases of conventional bilateral neck exploration, with a recognized role for ${ }^{99 \mathrm{~m}} \mathrm{Tc}$ sestamibi scintigraphy in depicting ectopic parathyroid lesions. Scintigraphy can also play a major role in guiding a targeted, minimally invasive parathyroidectomy. However, the ability to recognize multiple-gland disease (MGD) varies greatly depending on the imaging protocol used. Preoperative diagnosis of MGD is important to reduce the risks of conversion to bilateral surgery or failure. In this article we discuss imaging strategies before first surgery as well as in the case of repeat surgery for persistent or recurrent primary hyperparathyroidism. We describe a preferred algorithm and alternative options. Dualtracer ${ }^{99 \mathrm{~m}} \mathrm{Tc}$-sestamibi $/{ }^{123}$ I subtraction scanning plus neck ultrasound is the preferred first-line option. This approach should improve MGD detection and patient selection for minimally invasive parathyroidectomy. Second-line imaging procedures in case of negative or discordant first-line imaging results are presented. High detection rates can be obtained with ${ }^{18} \mathrm{~F}$-fluorocholine PET/CT or with 4-dimensional CT. The risk of false-positive results should be kept in mind, however. Adding a contrast-enhanced arterial-phase CT acquisition to conventional ${ }^{18} \mathrm{~F}$-fluorocholine PET/CT can be a way to improve accuracy. We also briefly discuss other localization procedures, including ${ }^{11} \mathrm{C}$-methionine PET/CT, MRI, ultrasound-guided fine-needle aspiration, and selective venous sampling for parathyroid hormone measurement.

Key Words: primary hyperparathyroidism; sestamibi; dual-isotope; subtraction; SPECT/CT; ${ }^{18}$ F-fluorocholine PET/CT

J Nucl Med 2021; 62:3S-12S

DOI: 10.2967/jnumed.120.245993

$\mathbf{P}$ rimary hyperparathyroidism (PHPT) is a common endocrine disorder resulting from the autonomous production of parathyroid hormone $(\mathrm{PTH})$ from 1 or more abnormal parathyroid glands (1-4). Its incidence increases with age and is higher in women $(2,4)$. In the United States and Western Europe, fewer than $20 \%$ of patients present with renal complications (kidney stones, nephrocalcinosis), skeletal complications (fracture, osteitis fibrosa

\footnotetext{
Received Aug. 14, 2020; revision accepted Oct. 21, 2020.

For correspondence or reprints, contact Elif Hindié (elif.hindie@chubordeaux.fr).

COPYRIGHT (C) 2021 by the Society of Nuclear Medicine and Molecular Imaging
}

cystica, bone pain), or symptomatic hypercalcemia; most cases of PHPT are incidentally discovered (2). However, imaging studies in asymptomatic patients may show kidney stones, osteoporosis, or vertebral fractures, and progression occurs in up to $40 \%$ of patients during follow-up $(3,4)$. PHPT is characterized by hypercalcemia and elevated or inappropriately normal serum PTH levels. A diagnosis of normocalcemic PHPT can be made only after the elimination of secondary causes of hyperparathyroidism (1-3).

PHPT is caused by a solitary parathyroid adenoma in $80 \%$ of cases, whereas multiple-gland disease (MGD), with mostly double adenomas or 4-gland hyperplasia, accounts for $15 \%-20 \%$ of cases and parathyroid cancer accounts for fewer than $1 \%$ of cases $(2,3)$. MGD is often sporadic (5) but can also be linked to a hereditary disease. Inherited forms of PHPT include multiple endocrine neoplasia (MEN) syndromes of types MEN1, MEN4, and MEN2A, hyperparathyroidism-jaw tumor syndrome $(\sim 15 \%$ risk of parathyroid carcinoma), and familial isolated PHPT (2).

Surgery is the only curative treatment for PHPT. Various medical therapies can increase bone mineral density or reduce serum levels of calcium, but no single drug can do both (2). Parathyroidectomy increases bone mineral density, decreases the risk of fracture, decreases the incidence of nephrolithiasis, and may halt the decline in renal function $(1-4,6)$. Surgery is indicated in any patient younger than 50 years old, any symptomatic patient, and asymptomatic patients with signs of subclinical end-organ involvement-with some variations between guidelines $(1,6)$. Parathyroid imaging studies have no role in establishing the diagnosis of PHPT $(1,6)$; however, imaging is very important for operative planning after the decision to proceed with parathyroidectomy is made $(1,6-8)$.

Here we discuss the aims of preoperative imaging and suggest an imaging algorithm for use before the first surgery as well as in the case of repeat surgery for persistent or recurrent disease.

\section{IMAGING IS RECOMMENDED BEFORE FIRST PARATHYROID SURGERY IRRESPECTIVE OF SURGICAL APPROACH}

The surgical approach to PHPT can vary from bilateral cervical exploration to minimally invasive parathyroidectomy (MIP). The choice depends on preoperative localization study findings, family history, the presence or absence of concomitant thyroid disease, and the preference of the surgeon (7). Parathyroid imaging has become a standard preoperative procedure for locating abnormal parathyroid tissue $(1,6-8)$. Sestamibi scintigraphy and neck ultrasound are the most widely used, often so in conjunction, seeking 
for concordance to increase accuracy $(1,6-8)$. Imaging is not a substitute for surgical expertise, as results can be negative or inaccurate or may locate only part of the hyperfunctioning parathyroid tissue. Parathyroid surgery requires expertise because the patient may harbor MGD $(2,3,5)$; in about $16 \%$ of patients, parathyroid lesions can be ectopic (9-11); the hyperfunctioning tissue may involve a supernumerary parathyroid gland $(11,12)$; nodular thyroid disease can make parathyroid surgery more difficult; and parathyroid tumors can be very small - increasingly so because of earlier diagnosis and surgical decisions, with a reported median weight of $0.5 \mathrm{~g}$ for adenomas (13). This evolution also leads to greater challenges for imaging techniques.

Although bilateral neck exploration without any preoperative imaging is curative in $92 \%-95 \%$ of patients (14) and minor ectopias can be easily depicted by an experienced surgeon (e.g., prolapsed superior gland in the tracheoesophageal groove or inferior gland in the thyrothymic ligament), some parathyroid glands present major ectopias (e.g., superior glands in a retroesophageal or retropharyngeal position; inferior glands that are undescended, within the carotid sheath, or overmigrated into the mediastinum; or parathyroid glands completely buried in the thyroid parenchyma) (12). The maneuvers to search for an elusive gland (15) may increase the risk of perioperative complications (e.g., transient/permanent hypoparathyroidism, wound infection, postoperative hemorrhage, or recurrent laryngeal nerve injury). Thus, preoperatively identifying an ectopic gland can reduce the extent of dissection in a sizable minority of patients and avoid some surgical failures (e.g., low thoracic parathyroid glands) $(9,10,16)$.

${ }^{99 \mathrm{~m}} \mathrm{Tc}$-sestamibi imaging has a recognized high sensitivity and high positive predictive value (PPV) for ectopic parathyroid lesions $(9,10)$.

\section{ADVANTAGES AND DISADVANTAGES OF TARGETED SURGERY: IMPLICATIONS REGARDING CHOICE OF IMAGING}

MIP and bilateral neck exploration are both appropriate surgeries $(6,7)$. A randomized study showed an advantage for unilateral surgery in terms of operative time and incidence of transient hypocalcemia, whereas the rate of failure was not significantly higher $(8.5 \%$ for unilateral surgery vs. $4.5 \%$ for bilateral surgery) (17). A limit to this comparison, however, is that only patients randomized to the unilateral group received a sestamibi scan (17). Bilateral surgery with preoperative imaging is associated with a higher success rate, a shorter operative time, and lower risks of complications than exploratory bilateral surgery (16).

The success of MIP depends on the ability to identify the $15 \%-20 \%$ of patients with MGD. Repeat surgeries are associated with increased costs and morbidity. The use of intraoperative PTH monitoring has been recommended (6). PTH concentrations may, however, decrease $(50 \%$ decrease 10 min after tumor resection) even though line imaging results. other lesions are still present (18). The mean MGD rates are $19.3 \%$ with bilateral exploration but only $5.3 \%$ with targeted surgery $(P<0.001)(19)$. Many studies recently emphasized that the risk of recurrence may be greater than previously believed. Lou et al. reported a recurrence rate of $14.8 \%$ over a 10 -y follow-up period (20).

Another point to consider is that MIP might require conversion to bilateral surgery in about $20 \%$ of cases (21). Conversion is often due to imaging failure (e.g., incorrect localization, missed MGD).

The success of the MIP approach can thus be heavily dependent on the use of a good preoperative imaging strategy. The role of imaging should be even more critical when access to intraoperative PTH is limited. In addition to accuracy, techniques proposed for routine preoperative imaging should be available, affordable, approved, and reimbursed by health insurance and should have low rates of contraindications.

Figure 1 shows the algorithm for preoperative imaging, proposing a first-line approach using neck ultrasound plus 1 radionuclide imaging technique. For radionuclide imaging, we indicate a preferred option and alternative options (Fig. 1), as discussed in the following paragraphs.

Neck ultrasound is easily available and can be performed by radiologists or trained surgeons and endocrinologists. It is a lowcost, nonirradiating technique that also offers valuable additional information on thyroid morphology. Its effectiveness strongly depends on the operator's skills. However, neck ultrasound is not accurate enough to be used alone, as it has low sensitivity for ectopic lesions (10) and MGD (22).

\section{WHY IS ${ }^{99 M}$ TC-SESTAMIBI/ ${ }^{123}$ I SUBTRACTION IMAGING BETTER OPTION THAN DUAL-PHASE SESTAMIBI SCANNING FOR GUIDING TARGETED SURGERY?}

The systematic review by Ruda et al. emphasized the role of ${ }^{99 \mathrm{~m}}$ Tc-sestamibi scintigraphy in PHPT but identified differences in detection sensitivity based on the underlying pathology:

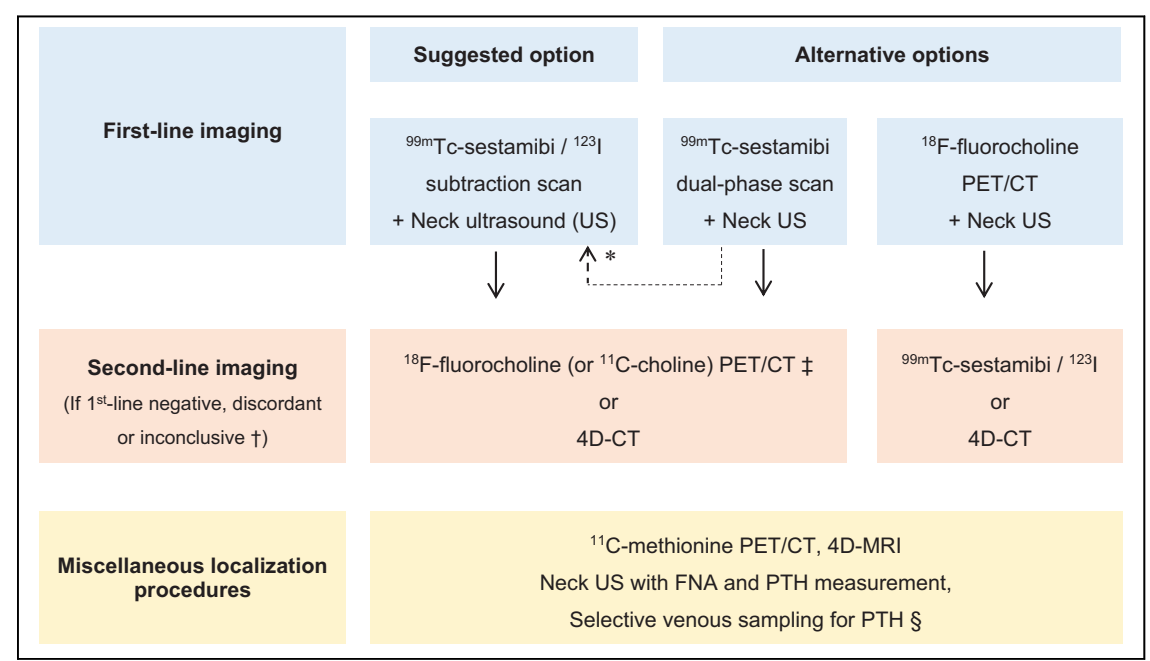

FIGURE 1. Algorithm for imaging investigations in primary hyperparathyroidism. See also Table 1 for suggested activities and acquisition protocol. *Dual-tracer subtraction scan can be positive in patients with previous negative dual-phase imaging results. ${ }^{\dagger}$ Suggestive lesion seen only on nuclear imaging in area not accessible to US should not be considered discordant or inconclusive. ${ }^{\ddagger}$ Contrast-enhanced arterial-phase CT acquisition can be added (it can improve PPV of PET/CT in difficult cases). ${ }^{\S}$ To be considered only in repeat surgery cases with negative first-line and second- 
sensitivities of $88.44 \%$ for solitary adenomas, $44.46 \%$ for multigland hyperplasia, and $29.95 \%$ for double adenomas (22). As pointed out by Kettle and O'Doherty, however, the systematic review did not separate the different ${ }^{99 \mathrm{~m}} \mathrm{Tc}$-sestamibi protocols (23).

Parathyroid scintigraphy protocols using a single-tracer dualphase technique and a dual-tracer subtraction technique were previously discussed (23-27). Regarding dual-tracer scintigraphy, ${ }^{99 \mathrm{~m}} \mathrm{Tc}$-sestamibi $/{ }^{123} \mathrm{I}$ subtraction imaging is the reference protocol $(23,24)$. With ${ }^{99 \mathrm{~m}} \mathrm{Tc}$-pertechnetate as the thyroid tracer, only successive acquisition is possible, and the subtraction image may be affected by artifacts because of patient motion between the 2 sets of acquisitions (25). Simultaneous acquisition of ${ }^{99 \mathrm{~m}} \mathrm{Tc}$-sestamibi and ${ }^{123} \mathrm{I}$ images reduces acquisition time, allows perfectly coregistered subtraction, and offers excellent sensitivity $(16,24,28,29)$.

Suggested acquisition protocols for ${ }^{99 \mathrm{~m}} \mathrm{Tc}$-sestamibi $/{ }^{123} \mathrm{I}$ dualisotope imaging and for ${ }^{99 \mathrm{~m}} \mathrm{Tc}$-sestamibi dual-phase imaging, with activities used, dosimetry, and camera occupation time, are shown in Table 1. Pinhole acquisition over the thyroid/parathyroid bed area offers enhanced count detection, spatial resolution, and sensitivity (30). SPECT/CT offers anatomic precision $(31,32)$.

Dual-phase ${ }^{99 \mathrm{~m}} \mathrm{Tc}$-sestamibi scintigraphy based on a comparison of early $(\sim 15 \mathrm{~min})$ and delayed $(\sim 2 \mathrm{~h})$ planar images misses MGD most of the time (33). Among 11 MGD patients, scintigraphy results were negative in 2 and incorrectly suggested a single adenoma in 9 (33). Even when dual-phase scintigraphy is combined with SPECT/CT, its ability to detect MGD remains unsatisfactory. Sandqvist et al. performed ${ }^{99 \mathrm{~m}} \mathrm{Tc}$-sestamibi SPECT/CT at $10 \mathrm{~min}$ and $90 \mathrm{~min}$ in 160 patients (34). Nine patients had MGD at surgery. Preoperative SPECT/CT had suggested a single adenoma in 8 of them (34). When dual-phase SPECT/CT was combined with 4-dimensional (4D) CT, MGD was predicted in only 3 of 9 patients (34). Therefore, we believe that single-tracer dual-phase scintigraphy cannot reliably guide targeted parathyroid surgery.

Comparative studies have consistently shown that dual-isotope ${ }^{99 \mathrm{~m}} \mathrm{Tc}$-sestamibi $/{ }^{123} \mathrm{I}$ subtraction imaging offers higher accuracy than ${ }^{99 \mathrm{~m}}$ Tc-sestamibi dual-phase imaging. Also, all 3 studies that used a pinhole collimator for this comparison obtained similar results $(28,29,35)$. Caveny et al. studied 37 patients $(28) .{ }^{99 \mathrm{~m}} \mathrm{Tc}-$ sestamibi $/{ }^{123}$ I subtraction imaging showed higher sensitivity than dual-phase imaging (94\% vs. $66 \% ; P<0.01)$, with fewer falsepositive results ( 0 vs. 2 ). There was no benefit of adding delayed images to the dual-tracer protocol (28). Krakauer et al. performed a head-to-head comparison in 91 patients (97 parathyroid lesions at surgery) (35). Sensitivities were $93 \%$ for ${ }^{99 \mathrm{~m}} \mathrm{Tc}$-sestamibi/ ${ }^{123} \mathrm{I}$ subtraction imaging and $65 \%$ for dual-phase scintigraphy $(P<$ $0.001)(35) .{ }^{123} \mathrm{I}$ is available in Europe on a daily basis and costs approximately U.S. $\$ 150$ plus delivery for 3 patient doses (35).

Simultaneous ${ }^{99 \mathrm{~m}} \mathrm{Tc}$-sestamibi/ ${ }^{123} \mathrm{I}$ imaging with pinhole acquisition has a high sensitivity for diagnosing MGD, exceeding 50\% in most studies (35-38). MGD is commonly characterized by the presence of glands of unequal size and intensity (36). Therefore, computer subtraction should be performed in gradual steps, with visual monitoring, avoiding oversubtraction. Figure 2 shows the importance of pinhole acquisition for optimal sensitivity, and Figure 3 offers an example of the anatomic information obtained with SPECT/CT. ${ }^{99 m}$ Tc-sestamibi and ${ }^{123} \mathrm{I} \mathrm{SPECT/CT} \mathrm{images} \mathrm{can} \mathrm{be}$ displayed side-by-side for visual comparison (Fig. 3). Subtraction can also be performed on 3-dimensional data $(39,40)$, but obtaining a well-balanced subtraction is technically more demanding than on planar pinhole images, and the possibility of edge artifacts should be kept in mind.
${ }^{99 m}$ Tc-sestamibi uptake by thyroid nodules complicates the interpretation of all parathyroid scintigraphy protocols. The ${ }^{123} \mathrm{I}$ scan can help by clarifying thyroid morphology and function, recognizing a false-positive result when the thyroid nodule takes up iodine. Sestamibi-avid/iodine-cold thyroid nodules carry a higher risk of malignancy, and fine-needle biopsy can aid in the decision about whether additional thyroid surgery is required.

The ${ }^{123} \mathrm{I}$ scan is necessary even in cases of previous thyroidectomy, as ${ }^{123}$ I will allow the correct identification of residual thyroid tissue (Fig. 4), which can be mistaken for a parathyroid lesion on neck ultrasound, ${ }^{99 \mathrm{~m}} \mathrm{Tc}$-sestamibi single-tracer scintigraphy, or other imaging modalities. Useless dissection in a neck that has undergone previous surgery can thus be avoided (Fig. 4).

\section{SECOND-LINE IMAGING STRATEGY WHEN SCINTIGRAPHY AND NECK ULTRASOUND RESULTS ARE NEGATIVE, DISCORDANT, OR INCONCLUSIVE}

\section{Discordant Imaging: Causes and Consequences}

With concordant sestamibi imaging and neck ultrasound, the success rate of MIP is high $(6,7)$. Patients with discordant imaging, in whom only 1 study is positive, or with diverging conclusions as to the site of a lesion(s) constitute a challenging subset of patients (41). These patients usually receive either routine bilateral surgery or MIP under intraoperative PTH monitoring, with a high risk of conversion to bilateral surgery (41).

Causes of discrepancies are multiple. Some limitations are inherent to neck ultrasound $(10,22)$. When neck ultrasound results are negative and ${ }^{99 \mathrm{~m}} \mathrm{Tc}$-sestamibi depicts a well-identified parathyroid lesion in an area less accessible to ultrasound imaging (e.g., retrotracheal, retroesophageal, or upper mediastinal), such a case should not be considered discordant or inconclusive. Some parathyroid lesions may have low ${ }^{99 \mathrm{~m}} \mathrm{Tc}$-sestamibi uptake because of their consistency (e.g., cystic lesions) or low content in oxyphil cells (25). With a dual-phase technique, negativity may also result from rapid tracer washout (25). Factors associated with difficult identification and characterization with either technique can also lead to discrepancies; these include a small parathyroid lesion or the presence of nodular thyroid disease. In MGD, discrepancies are frequent (41) because of limitations of techniques (33) or "satisfaction of search" (42). Finally, the experience of the operator also plays an important role (e.g., parathyroid lesions with atypical ultrasound features) (42).

Discordance can sometimes be resolved by a second neck ultrasound performed by an experienced operator aware of sestamibi findings (42). More generally, the order in which neck ultrasound and sestamibi imaging should be performed has been investigated little. Because of widespread availability, neck ultrasound is often obtained first. In a retrospective analysis of 63 patients, the sensitivity and PPV of neck ultrasound were better when it was performed after ${ }^{99 \mathrm{~m}} \mathrm{Tc}$-sestamibi SPECT/CT $(90.9 \%$ and $100 \%$ vs. $56.6 \%$ and $72.2 \%$, respectively; $P<0.05$ ), whereas the performance of ${ }^{99 \mathrm{~m}} \mathrm{Tc}$-sestamibi SPECT/CT was not improved by knowledge of neck ultrasound results (43). Validation of these findings in a prospective setting may have important practical consequences.

Although the risk of MGD is somewhat higher with discordant imaging, most patients ( $\sim 70 \%)$ have a single adenoma at surgery (41). Therefore, instead of choosing a more extensive surgical exploration, the use of second-line imaging would be desirable (43), as suggested in the algorithm (Fig. 1). 
TABLE 1

Summary of Techniques Used for Parathyroid Scintigraphy and PET/CT

\begin{tabular}{|c|c|c|c|c|c|}
\hline Technique & Radiopharmaceutical* & $\begin{array}{c}\text { Effective } \\
\text { dose }(\mathrm{mSv})^{\dagger}\end{array}$ & $\begin{array}{c}\text { Protocol of } \\
\text { administration }\end{array}$ & $\begin{array}{l}\text { Suggested } \\
\text { acquisition } \\
\text { protocol }\end{array}$ & $\begin{array}{l}\text { Total } \\
\text { acquisition time }\end{array}$ \\
\hline \multirow[t]{4}{*}{$\begin{array}{l}{ }^{99 m} \text { Tc-sestamibi }^{123}{ }^{123} \\
\text { (subtraction) }\end{array}$} & ${ }^{123} \mathrm{I}(\sim 12 \mathrm{MBq})$ & 1.5 & $\begin{array}{l}\text { T0: }{ }^{123} \text { I (intravenous } \\
\text { or oral) }\end{array}$ & $\begin{array}{l}{ }^{99 \mathrm{~m}} \mathrm{Tc} \text { and }{ }^{123} \mathrm{I} \\
\text { simultaneous dual- } \\
\text { isotope acquisition } \\
\text { starting } 3-5 \text { min } \\
\text { after }{ }^{99 m} \mathrm{Tc}^{-} \\
\text {sestamibi injection }{ }^{\ddagger}\end{array}$ & $<1 \mathrm{~h}$ \\
\hline & $\begin{array}{l}{ }^{99 m} \text { Tc-sestamibi } \\
(\sim 600 \mathrm{MBq})\end{array}$ & 5.4 & $\begin{array}{c}\mathrm{T}+2 \mathrm{~h}:{ }^{99 \mathrm{~m}} \mathrm{Tc}- \\
\text { sestamibi } \\
\text { (intravenous) }\end{array}$ & $\begin{array}{l}\text { Image of thyroid/ } \\
\text { parathyroid bed } \\
\text { with pinhole } \\
\text { collimator (15 } \\
\text { min) }\end{array}$ & \\
\hline & & & & $\begin{array}{l}\text { Planar image of } \\
\text { neck and } \\
\text { mediastinum ( } 5 \\
\text { min })^{\S}\end{array}$ & \\
\hline & & & & $\begin{array}{l}\text { Then, dual-isotope } \\
\text { SPECT/CT acqui- } \\
\text { sition ( 25 min) }\end{array}$ & \\
\hline \multirow[t]{4}{*}{$\begin{array}{l}{ }^{99 m} \text { Tc-sestamibi } \\
\text { (dual-phase) }\end{array}$} & $\begin{array}{l}{ }^{99 m} \text { Tc-sestamibi } \\
(740-900 \mathrm{MBq})\end{array}$ & $6.7-8.1$ & $\begin{array}{c}\text { T0: }{ }^{99 m} \text { Tc-sestamibi } \\
\text { (intravenous) }\end{array}$ & $\begin{array}{l}\mathrm{T}+15 \text { min (early } \\
\text { phase); planar } \\
\text { image of neck } \\
\text { and mediastinum } \\
(5 \mathrm{~min})^{\S}\end{array}$ & $\sim 90$ min in 2 sessions \\
\hline & & & & $\begin{array}{l}\text { Image of thyroid/ } \\
\text { parathyroid bed } \\
\text { with pinhole } \\
\text { collimator ( } 15 \\
\text { min) }\end{array}$ & \\
\hline & & & & $\begin{array}{l}\mathrm{T}+2 \mathrm{~h} \text { (delayed } \\
\text { phase); same } \\
\text { protocol as early } \\
\text { phase }\end{array}$ & \\
\hline & & & & $\begin{array}{l}\text { SPECT/CT ( 25 } \\
\text { min) at early, } \\
\text { delayed, or both } \\
\text { phases }\end{array}$ & \\
\hline \multirow[t]{3}{*}{$\begin{array}{l}{ }^{18} \text { F-fluorocholine } \\
\text { PET/CT } \\
( \pm \text { CECT) }\end{array}$} & $\begin{array}{c}{ }^{18} \text { F-fluorocholine } \\
(100-200 \mathrm{MBq} \\
\text { or } 2-3 \mathrm{MBq} / \mathrm{kg})\end{array}$ & $2.0-4.0$ & $\begin{array}{l}\text { TO: }{ }^{18} \mathrm{~F}- \\
\text { fluorocholine } \\
\text { (intravenous) }\end{array}$ & $\begin{array}{l}\text { PET acquisition } \\
\text { starting } \sim 45 \text { min } \\
\text { (30-60 min) after } \\
\text { injection }\end{array}$ & $20-30 \mathrm{~min}$ \\
\hline & & & & $\begin{array}{l}\text { Nonenhanced CT } \\
\text { from mandible to } \\
\text { carina }\end{array}$ & \\
\hline & & & & $\begin{array}{l}\text { If arterial-phase } \\
\text { CECT is added, } \\
\text { then acquisition } \\
\text { starts } \sim 30 \mathrm{~s} \\
\text { ( } 25-40 \mathrm{~s}) \text { after } \\
\text { beginning of } \\
\text { contrast medium } \\
\text { injection }\end{array}$ & \\
\hline
\end{tabular}

*Values in parentheses are activities.

${ }^{\dagger}$ Not including CT dose (25). For ${ }^{123}$ I, we considered thyroid uptake of $20 \%$.

${ }^{\ddagger}$ Example of nonoverlapping windows (29): for ${ }^{99 \mathrm{~m}} \mathrm{Tc}, 140 \mathrm{keV} \pm 7 \%(130-150 \mathrm{keV})$; for ${ }^{123} \mathrm{I}, 159 \mathrm{keV}-4 \%$ to $+10 \%$ (153-175 keV).

$\S$ Includes submandibular salivary glands and upper part of myocardium.

"Early phase ( $\sim 5$ min after injection) is additionally obtained by some authors.

CECT = contrast-enhanced CT; $\mathrm{T}=$ time. 


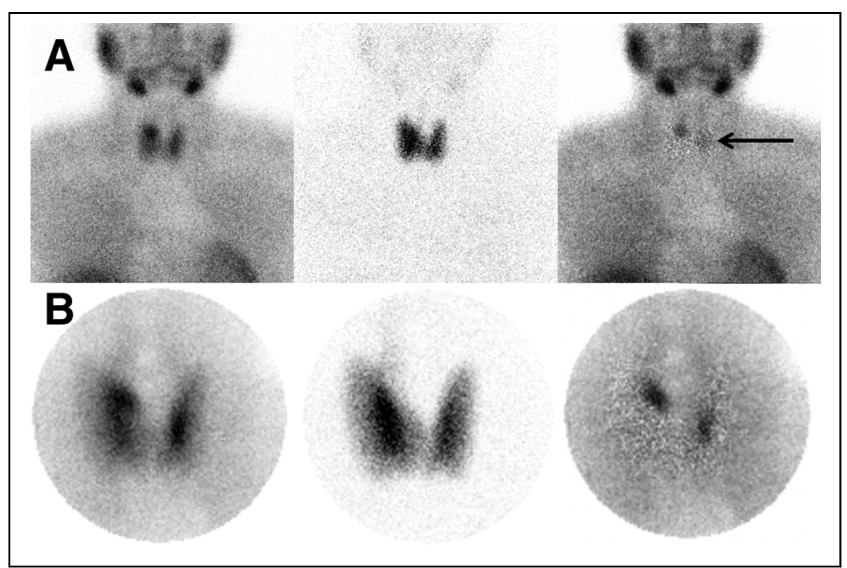

FIGURE 2. Simultaneous dual-tracer ${ }^{99 \mathrm{~m}} \mathrm{Tc}$-sestamibi and ${ }^{123} \mathrm{I}$ scan in 39-y-old patient with PHPT. (A) Parallel-hole collimator images with ${ }^{99} \mathrm{Tc}-$ sestamibi, ${ }^{123}$, and subtraction. Parallel-hole subtraction image shows residual focus on right side of neck, barely visible focus on left side (arrow), and no ectopic foci. (B) Pinhole images over thyroid area with ${ }^{99}$ Tc-sestamibi, ${ }^{123} \mathrm{l}$, and subtraction. Pinhole subtraction image clearly shows 2 residual foci. Surgery confirmed diagnosis of double adenomas, and calcium level at 6 mo was normal. This example shows better resolution offered by pinhole images and reveals importance of computer subtraction, as visual comparison alone could have missed left-side focus. Computer subtraction should be well balanced, avoiding oversubtraction.

\section{Implications of Negative Parathyroid Scan and Neck Ultrasound Results}

Although patients with nonlocalizing imaging results remain surgical candidates ( 6 ), an experienced multidisciplinary team should be entrusted with the case. Several studies have indeed reported that patients with negative imaging results may require more extensive exploratory surgery (44) and are exposed to a higher rate of surgical failure $(44,45)$. In a large series from the Mayo Clinic, surgery was curative in $97.5 \%$ of patients with localization on the ${ }^{99 \mathrm{~m}} \mathrm{Tc}$-sestamibi $/{ }^{123} \mathrm{I}$ scan, compared with $90.4 \%$ when the scan results were negative $(P<0.001)(45)$.

\section{Dual-Tracer Subtraction Imaging in Patients with Negative Dual-Phase Scintigraphy Results}

As mentioned in the algorithm (Fig. 1), obtaining positive ${ }^{99 \mathrm{~m}} \mathrm{Tc}$-sestamibi $/{ }^{123} \mathrm{I}$ scan results after negative single-tracer imaging results is not rare (e.g., when negative dual-phase imaging results are due to rapid tracer washout) (46).

\section{${ }^{18}$ F-Fluorocholine (or ${ }^{11} \mathrm{C}$-Choline) PET/CT}

After incidental findings of a parathyroid adenoma during ${ }^{11} \mathrm{C}$ choline PET imaging for prostate cancer, many teams investigated ${ }^{18} \mathrm{~F}$-fluorocholine (or ${ }^{11} \mathrm{C}$-choline) PET in PHPT patients with negative/inconclusive ${ }^{99 \mathrm{~m}} \mathrm{Tc}$-sestamibi and neck ultrasound results (47-52). These PET tracers open new avenues for radionuclide imaging of parathyroid glands $(27,39,53,54)$. The best imaging time for ${ }^{18} \mathrm{~F}$-fluorocholine PET is still subject to discussion, but most parathyroid lesions are better defined (better lesion-to-thyroid contrast) at $60 \mathrm{~min}$ than at $5 \mathrm{~min}$ (55). Some teams image at more than 1 time, whereas most use single-time-point imaging between $30 \mathrm{~min}(48,51)$ and $60 \mathrm{~min}(49)$ after injection.

Most studies are retrospective, with many patients not being offered surgery, rendering measurements of test performance difficult. Quak et al. prospectively investigated ${ }^{18} \mathrm{~F}$-fluorocholine $\mathrm{PET} / \mathrm{CT}$ in 25 patients with negative/inconclusive dual-phase ${ }^{99 \mathrm{~m}} \mathrm{Tc}$-sestamibi (including delayed SPECT/CT) and neck

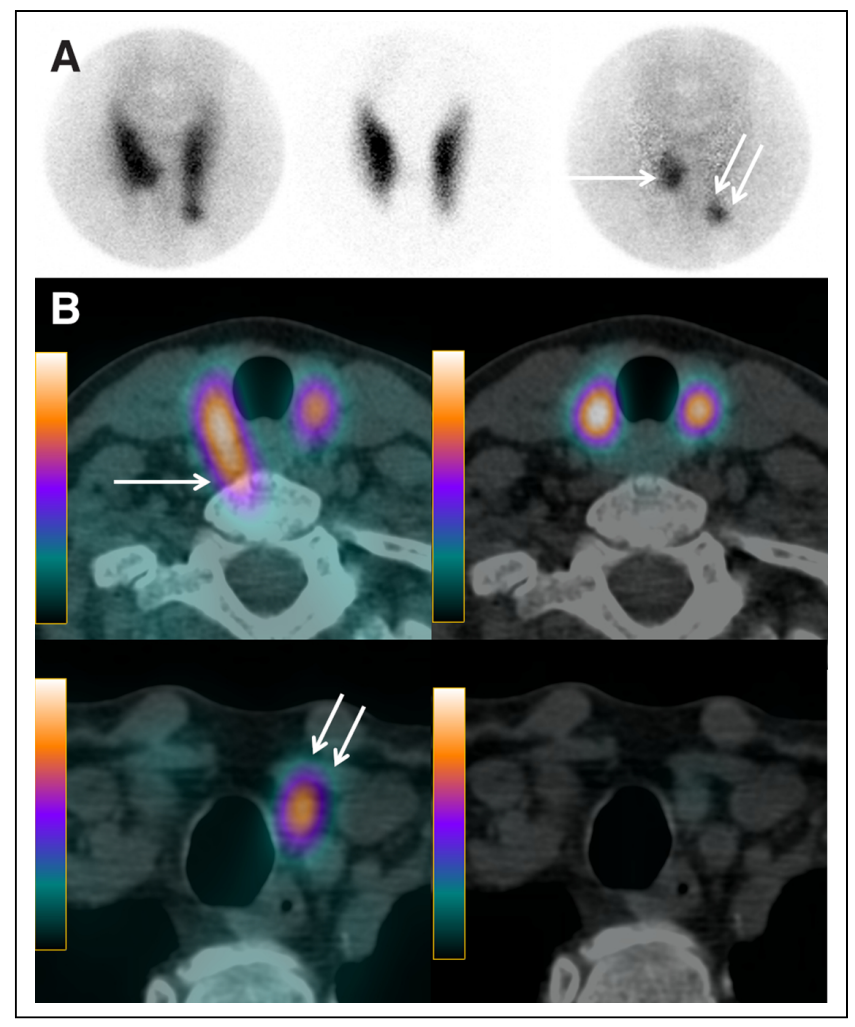

FIGURE 3. Simultaneous dual-tracer ${ }^{99 m}$ Tc-sestamibi and ${ }^{123} \mathrm{~s}$ scan in 62-y-old patient with PHPT. (A) Pinhole images of thyroid area with ${ }^{99 \mathrm{~m}} \mathrm{Tc}$ sestamibi, ${ }^{123} \mathrm{I}$, and subtraction. Pinhole subtraction image clearly identifies 2 residual foci: 1 at inner part of lower third of right thyroid lobe (arrow) and other at lower pole of left thyroid lobe (double arrow). (B) Axial SPECT/ CT fusion images with ${ }^{99 m}$ Tc-sestamibi (right) and ${ }^{123} \mathrm{I}$ (left), obtained at 2 different levels. On SPECT/CT axial views, right parathyroid lesion is located posteriorly, in paraesophageal position (arrow). This location is typical of prolapsed superior parathyroid gland (minor ectopia). Left inferior parathyroid lesion (double arrow) is located below lower pole of left thyroid lobe. Calcium level 6 mo after resection of 2 adenomas was normal.

ultrasound results (49). Twenty-four patients received surgery. Importantly, surgery was targeted in 18 cases. Analysis per lesion yielded a sensitivity of ${ }^{18} \mathrm{~F}$-fluorocholine of $91.3 \%$ and a PPV of $87.5 \%$ (49). Only 1 patient had MGD, fewer than expected in this setting $(41,44,45)$, calling into question the sensitivity of ${ }^{18} \mathrm{~F}$-fluorocholine PET/CT for MGD (56). With regard to surgical outcomes, surgical failure occurred in 3 patients (13\%) (49). The authors warned about the risk associated with considering equivocal ${ }^{18} \mathrm{~F}$-fluorocholine PET/CT results positive (49).

Parathyroid lesions identified by second-line ${ }^{18} \mathrm{~F}$-fluorocholine PET/CT imaging are often small or deeply seated or have a bony interposition (Fig. 5). Lower resolution and attenuation may contribute to the negativity of sestamibi imaging results. With dualphase ${ }^{99 \mathrm{~m}} \mathrm{Tc}$-sestamibi imaging, rapid washout can also be a factor.

\section{${ }^{11}$ C-Methionine PET/CT}

Some studies reported good sensitivity when the amino acid tracer ${ }^{11} \mathrm{C}$-methionine was used for second-line imaging (57), but this tracer is less available than ${ }^{18} \mathrm{~F}$-fluorocholine. The 2 tracers were compared in patients with negative/inconclusive ${ }^{99 \mathrm{~m}} \mathrm{Tc}$-sestamibi SPECT results (58). Surgery was successful in 21 of 26 patients $(81 \%)$. Per-lesion sensitivity was superior with ${ }^{18} \mathrm{~F}$-fluorocholine versus ${ }^{11} \mathrm{C}$-methionine $(84 \%$ vs. $72 \% ; P=0.001)$. The PPVs were $93 \%$ and $95 \%$, respectively (58). 

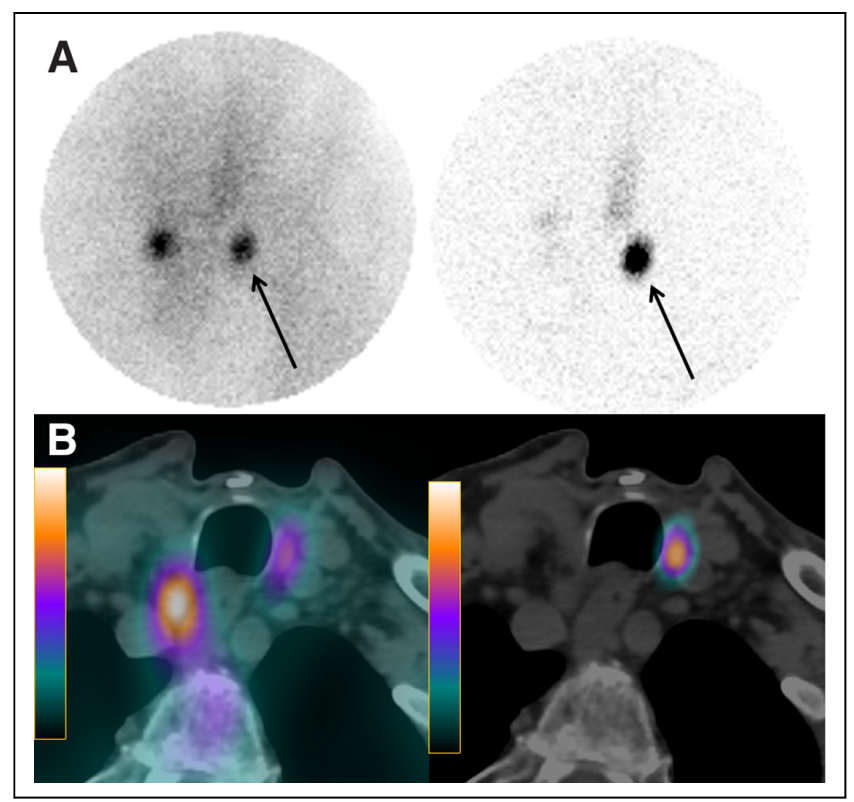

FIGURE 4. 84-y-old patient with PHPT and history of total thyroidectomy. Neck ultrasound results were negative. Simultaneous dual-tracer ${ }^{99 m}$ Tc-sestamibi and ${ }^{123}$ | parathyroid scan was performed after patient was instructed to withhold thyroid hormone therapy for 2 wk. (A) Pinhole images of neck show two ${ }^{99 \mathrm{~m}} \mathrm{Tc}$-sestamibi-avid foci (1 on each side of neck), but ${ }^{123}$ I scan clearly shows that focus on left side corresponds to thyroid remnant (arrow). (B) ${ }^{99 \mathrm{~m}} \mathrm{Tc}$-sestamibi and ${ }^{123}$ I SPECT/CT axial views without subtraction reveal posteriorly seated right parathyroid lesion and left thyroid remnant. Targeted surgery could be performed with resection of 600-mg right parathyroid adenoma.

\section{Parathyroid 4-Dimensional CT}

4D CT uses the dynamics of contrast enhancement (noncontrast phase, followed by contrast-enhanced arterial and venous CT
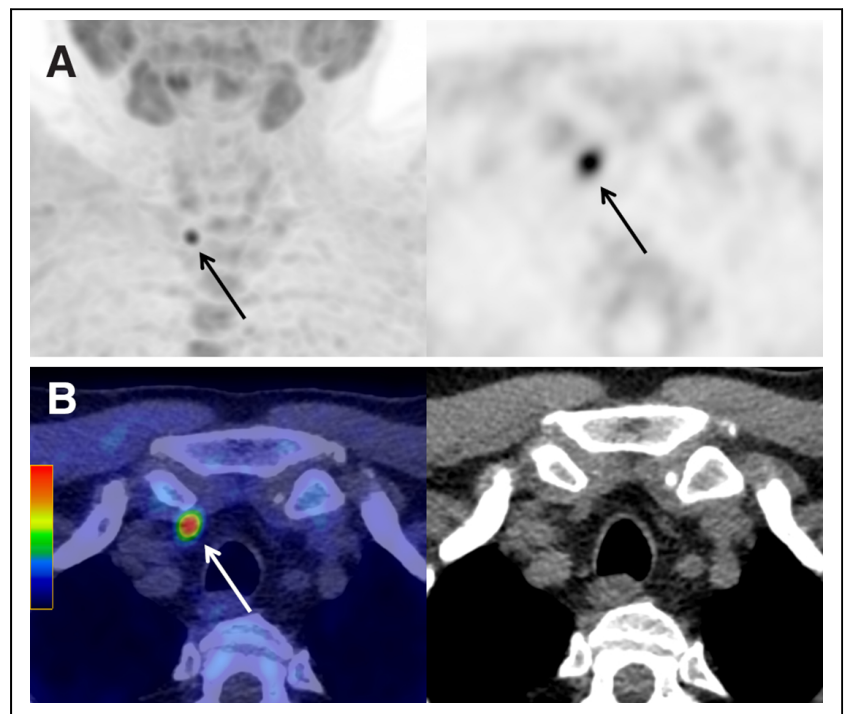

FIGURE 5. ${ }^{18} \mathrm{~F}$-fluorocholine PET/CT performed $35 \mathrm{~min}$ after intravenous injection of ${ }^{18} \mathrm{~F}$-fluorocholine in 71 -y-old patient with PHPT. Results of neck ultrasonography and dual-phase ${ }^{99 \mathrm{~m}} \mathrm{Tc}$-sestamibi parathyroid scan performed at another institution before referral were negative. ${ }^{18} \mathrm{~F}$-fluorocholine PET (A) with maximum-intensity-projection and axial view images show ${ }^{18} \mathrm{~F}$-fluorocholine-avid focus corresponding on axial PET/CT fusion and $\mathrm{CT}$ images (B) to small tissue lesion behind right sternoclavicular junction (arrows). Parathyroid adenoma $(500 \mathrm{mg}$ ) was resected. phases) to identify abnormal parathyroid glands. A sensitivity of $89 \%$ was reported in patients with negative first-line imaging results but with a PPV of $74 \%$ (59).

Some limitations of 4D CT need to be recognized. Discordance with intraoperative findings was found in 123 of 411 patients (30\%) (60). MGD, lesions of less than or equal to $10 \mathrm{~mm}$, nodular thyroid, and parathyroid lesion in the inferior position were independently associated with discordant 4D CT results.

4D CT is probably not well adapted to routine first-line imaging in PHPT, as it requires substantial expertise, delivers a high radiation dose to the neck and upper thorax, and requires injection of iodinated contrast medium in a population in whom renal impairment is not uncommon.

\section{MRI and PET/MRI}

Parathyroid MRI techniques are also evolving. Some teams investigated the use of ${ }^{18} \mathrm{~F}$-fluorocholine PET/MRI $(50,61,62)$, with (61) or without (62) MRI contrast media. More studies are needed to define the role of this technique.

\section{${ }^{18}$ F-Fluorocholine PET/CT with Contrast Enhancement}

Piccardo et al. prospectively investigated the value of fully integrated ${ }^{18} \mathrm{~F}$-fluorocholine PET with 4D CT in 44 PHPT patients with negative/inconclusive first-line imaging results (63). The detection rate with ${ }^{18}$ F-fluorocholine PET/4D CT (72.7\%) was significantly higher $(P<0.05)$ than with conventional ${ }^{18} \mathrm{~F}$-fluorocholine PET/CT $(56.8 \%)$ or 4D CT $(54.5 \%)(63)$. Six lesions missed by ${ }^{18} \mathrm{~F}$-fluorocholine PET but identified by ${ }^{18} \mathrm{~F}$-fluorocholine PET/4D CT were very close to the thyroid. It is worth mentioning that imaging started $10 \mathrm{~min}$ after ${ }^{18} \mathrm{~F}$ fluorocholine injection - an approach that might not offer the highest parathyroid-to-thyroid contrast. In a retrospective analysis, Pretet et al. found the sensitivity of ${ }^{18} \mathrm{~F}$-fluorocholine PET/CT superior to that of 4D CT ( $88 \%$ vs. $66 \% ; P=0.01)$, with no significant improvement with integrated ${ }^{18}$ F-fluorocholine PET/4D CT (sensitivity, 92\%) (64).

At University Hospitals of Bordeaux, ${ }^{18} \mathrm{~F}$-fluorocholine PET/CT for inconclusive first-line imaging is performed using nonenhanced CT plus a contrast-enhanced arterial-phase CT acquisition, in the absence of contraindications, with the purpose of reducing potential ${ }^{18}$ F-fluorocholine false-positive results from reactive lymph nodes (Fig. 6). False-positive results with ${ }^{18} \mathrm{~F}$-fluorocholine PET are mostly due to thyroid nodules (47) and reactive lymph nodes $(49,55,65)$. The precontrast CT discriminates parathyroid lesions from the thyroid (higher spontaneous density), whereas the arterial phase best discriminates parathyroid lesions (moderate to high enhancement) from lymph nodes (low enhancement) (Fig. 6). Eliminating the venous phase of conventional 4D CT helps reduce the radiation dose (65).

Christakis et al. reported on 12 patients who had persistent/ recurrent PHPT and who received surgery on the basis of ${ }^{18} \mathrm{~F}$-fluorocholine-avid lesions (65). Seven patients were cured, whereas 5 (42\%) had persistent hypercalcemia. Retrospectively, the arterialphase enhancements of the associated CT were significantly different between cured patients and not-cured patients $(P=0.007)$. The authors concluded that grading of the arterial phase of CT can help differentiate between true adenomas and lymph nodes (65).

\section{IS IT TOO EARLY TO PROPOSE ${ }^{18} \mathrm{~F}$-FLUOROCHOLINE PET/CT AS FIRST-LINE IMAGING?}

Some teams reported on ${ }^{18} \mathrm{~F}$-fluorocholine (or ${ }^{11} \mathrm{C}$-choline) as first-line imaging in PHPT (66-70). Four studies had greater than or equal to 50 surgery patients and a prospective design $(67,68-70)$. 


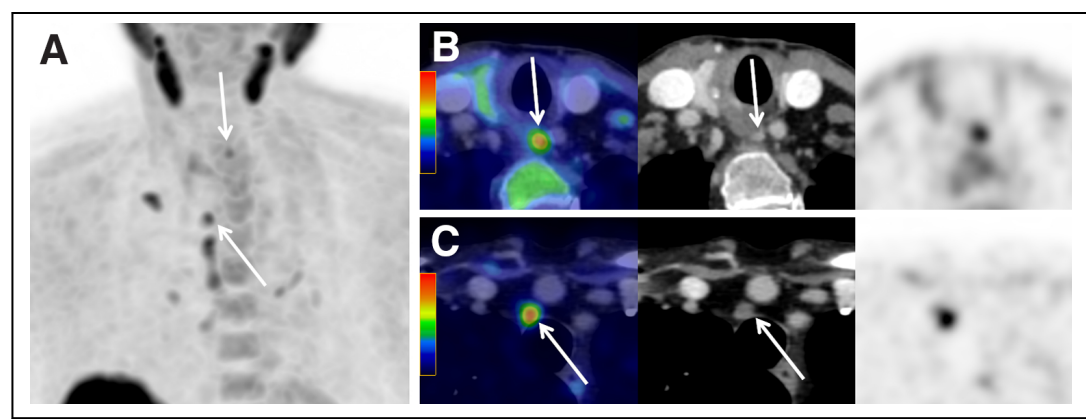

FIGURE 6. ${ }^{18} \mathrm{~F}$-fluorocholine PET/CT in 74-y-old patient with PHPT. Neck ultrasonography described doubtful left inferior parathyroid lesion, and ${ }^{99 \mathrm{~m}} \mathrm{Tc}$-sestamibi $/{ }^{123}$ I subtraction scintigraphy results were negative. ${ }^{18} \mathrm{~F}$-fluorocholine PET/CT included conventional nonenhanced plus contrast-enhanced arterial-phase CT acquisitions. (A) Maximum-intensity-projection ${ }^{18} \mathrm{~F}$-fluorocholine PET image reveal faint cervical focus (superior arrow) and multiple mediastinal foci (inferior arrow). (B) PET/CT fusion and arterial-phase contrast-enhanced CT (CECT) and PET axial images show choline-avid lesion with high contrast enhancement contiguous to left posterior side of esophagus, suggestive of ectopic parathyroid lesion (arrows). (C) PET/CT fusion and arterial-phase CECT and PET axial images of superior mediastinum show choline-avid lymph node with low contrast enhancement (arrows). At surgery, retroesophageal parathyroid adenoma was resected.

Thanseer et al. studied 54 patients (67). The detection rate was higher with ${ }^{18} \mathrm{~F}$-fluorocholine PET/CT (imaging at 15 and $60 \mathrm{~min})$ than with dual-phase ${ }^{99 \mathrm{~m}} \mathrm{Tc}$-sestamibi imaging (100\% vs. $76.4 \%$ ), but with more false-positive results (4 vs. 1) (67). Surgery failed in 2 patients (no lesion found), and no patient had MGD (67).

Beheshti et al. compared ${ }^{18} \mathrm{~F}$-fluorocholine PET/CT (imaging at 60 and $110 \mathrm{~min}$ ) and dual-phase ${ }^{99 \mathrm{~m}} \mathrm{Tc}$-sestamibi (or ${ }^{99 \mathrm{~m}} \mathrm{Tc}$-tetrofosmin) imaging in 100 patients $(68)$. ${ }^{99 \mathrm{~m}} \mathrm{Tc}$-tetrofosmin is adequate for subtraction but not for dual-phase scanning, as it has a slow washout from the thyroid $(25,26)$. Surgery was performed in 76 patients with intraoperative PTH monitoring. With ${ }^{18} \mathrm{~F}$-fluorocholine, the sensitivity for parathyroid adenomas was $93.7 \%$ and the PPV was $90.2 \%$. With ${ }^{99 \mathrm{~m}}$ Tc-sestamibi $/{ }^{99 \mathrm{~m}} \mathrm{Tc}$-tetrofosmin, the sensitivity was $60.8 \%$ and the PPV was $94.1 \%$. Ten patients had MGD; how many cases were recognized preoperatively was not stated (68).

Cuderman et al. (the latest report from this team) compared ${ }^{18} \mathrm{~F}$ fluorocholine PET/CT (imaging at 5 and $60 \mathrm{~min}$ ) and a dual-phase ${ }^{99} \mathrm{~m}$ Tc-sestamibi plus ${ }^{99 \mathrm{~m}}$ Tc-pertechnetate scan in 188 patients (70). Surgery was offered to 103 patients. ${ }^{18} \mathrm{~F}$-fluorocholine had a higher sensitivity (92\% vs. $65 \%)$, notably in patients with small adenomas or MGD. Surgery failed in 8 patients (70).

In these studies, ${ }^{18}$ F-fluorocholine imaging had a higher sensitivity than dual-phase ${ }^{99 \mathrm{~m}} \mathrm{Tc}$-sestamibi imaging but a higher rate of false-positive results $(67,68,70)$. Many patients did not receive surgery. Perhaps more importantly, at present there is no evidence that first-line imaging with ${ }^{18} \mathrm{~F}$-fluorocholine PET/ CT improves surgical outcomes or, notably, the rate of failed surgery.

No study compared ${ }^{18} \mathrm{~F}$-fluorocholine PET/CT and ${ }^{99 \mathrm{~m}} \mathrm{Tc}$-sestamibi $/{ }^{123} \mathrm{I}$ subtraction imaging as first-line imaging. In the only study that compared ${ }^{11} \mathrm{C}$-choline PET/CT and ${ }^{99 \mathrm{~m}} \mathrm{Tc}$-sestamibi $/{ }^{123} \mathrm{I}$ subtraction imaging as first-line imaging, there was no significant difference in sensitivity (69).

The strengths of ${ }^{18} \mathrm{~F}$-fluorocholine PET/CT imaging are shorter imaging time, lower radiation dose (Table 1), and high sensitivity. Sensitivity can be further increased with novel technologies (71), such as digital PET systems (as in Figs. 5 and 6). Potential drawbacks of ${ }^{18} \mathrm{~F}$-fluorocholine PET/CT imaging, on the other hand, are lower availability, much higher cost, currently no listed Food and Drug Administration approval for parathyroid imaging, no thyroid tracer for comparison of risks of false-positive results from thyroid nodules, and uptake by inflammatory lymph nodes.

As stated previously, ${ }^{99 \mathrm{~m}} \mathrm{Tc}$-sestamibi has a high PPV for ectopic parathyroid lesions (9). Surgeons are very confident when embarking on thoracoscopy/thoracotomy based on ${ }^{99 \mathrm{~m}}$ Tc-sestamibi SPECT/CT findings. Experience with ${ }^{18} \mathrm{~F}$-fluorocholine PET/ CT imaging is still limited. Uptake of ${ }^{18} \mathrm{~F}$-fluorocholine by inflammatory/granulomatous mediastinal lymph nodes is not rare and might reduce the ability to identify true ectopic parathyroid lesions and label them as such. Contrast-enhanced arterial-phase CT can improve the PPV of ${ }^{18} \mathrm{~F}$-fluorocholine PET/CT (Fig. 6). However, this additional contrast-enhanced CT acquisition has logistical implications, potential side effects, and dose implications, so that it is better reserved for second-line imaging or repeat surgery cases.

\section{LOCALIZATION PROCEDURES BEFORE REPEAT SURGERY FOR PERSISTENT OR RECURRENT HYPERPARATHYROIDISM}

Hypercalcemia within 6 mo of surgery defines persistent, as opposed to recurrent, PHPT. Repeat surgery should be decided carefully, as its complication rate is higher than that for a first surgery $(6,72)$. Concordant functional and anatomic imaging studies should be sought (7). Detailed review of surgical reports and previous imaging results is key to successful interpretation.

The algorithm in Figure 1 also applies to repeat surgery.

\section{Sestamibi Imaging and Neck Ultrasound Before Repeat Surgery}

In a prospective study, the sensitivity of dual-phase ${ }^{99 \mathrm{~m}} \mathrm{Tc}$-sestamibi SPECT/CT was $19 \%$, whereas the sensitivity of ${ }^{99 \mathrm{~m}} \mathrm{Tc}$-sestamibi/ ${ }^{123}$ I scintigraphy (planar only) was $59 \%(P<0.01)(73)$. Sensitivity can be further improved with pinhole imaging (74), and complementary SPECT/CT is necessary given the high prevalence of ectopic glands (27). In MEN1, the possibility of more than 1 site of recurrence should be considered, as with renal hyperparathyroidism (75).

Repeat neck ultrasound should be performed by an experienced operator. Ultrasound-guided fine-needle aspiration for PTH washout can be considered in difficult cases $(7,72)$.

\section{${ }^{18}$ F-Fluorocholine PET/CT and 4D CT Before Repeat Surgery}

In a retrospective analysis of patients with prior neck surgery and negative/inconclusive first-line imaging results (76), the sensitivity of ${ }^{18}$ F-fluorocholine PET/CT was $96 \%$ and the PPV was $77 \%$. With 4D CT, the sensitivity was $75 \%$ and the PPV was $80 \%$. The surgical success rate was $73 \%$. Thus, although both techniques have a high sensitivity, the risk of falsepositive findings is also high. Combining the 2 studies or adding arterial-phase CT acquisition to conventional ${ }^{18} \mathrm{~F}$-fluorocholine 
PET/CT to improve the PPV in this challenging population is desirable (65).

\section{${ }^{11}$ C-Methionine PET/CT Before Repeat Surgery}

${ }^{11} \mathrm{C}$-methionine $\mathrm{PET} / \mathrm{CT}$ was positive in 6 of 15 patients $(40 \%)$ with prior negative dual-phase ${ }^{99 \mathrm{~m}} \mathrm{Tc}$-sestamibi imaging results (77).

\section{Selective Venous Sampling for PTH Before Repeat Surgery}

Selective venous sampling for PTH before repeat surgery should be considered only when imaging studies are unhelpful $(7,72)$. It is highly reliant on the technique used and the operator's expertise, with variable results $(73,78)$. The yield when first-line and second-line imaging results, including ${ }^{18} \mathrm{~F}$-fluorocholine PET/ CT results, are inconclusive (algorithm in Fig. 1) is currently unknown and deserves investigation before conclusions regarding the role of this invasive technique can be drawn.

\section{CONCLUSION}

Preoperative imaging in PHPT can identify ectopic parathyroid glands and is always required. A ${ }^{99} \mathrm{~m}$ Tc-sestamibi $/{ }^{123} \mathrm{I}$ subtraction scanning provides better sensitivity for MGD than a dual-phase ${ }^{99 m}$ Tc-sestamibi scan. This approach should be helpful in improving outcomes with targeted parathyroid surgery, reducing the rates of surgical conversions as well as failures. When scintigraphy and neck ultrasound results are negative, ${ }^{18} \mathrm{~F}$-fluorocholine PET/CT or 4D CT still offers high detection rates. The risk of false-positive findings should be kept in mind, however, and strategies to reduce this risk should be encouraged.

\section{DISCLOSURE}

No potential conflict of interest relevant to this article was reported.

\section{ACKNOWLEDGMENT}

In accordance with French Jardé Law, the review board of University Hospitals of Bordeaux waives the requirement for informed consent for review articles and retrospective use of anonymized data obtained in the course of routine clinical care.

\section{KEY POINTS}

QUESTION: How can radionuclide imaging best guide surgery in patients with PHPT?

PERTINENT FINDINGS: ${ }^{99 \mathrm{~m}} \mathrm{Tc}$-sestamibi $/{ }^{123}$ I subtraction scanning provides better sensitivity than dual-phase ${ }^{99 \mathrm{~m}} \mathrm{Tc}$-sestamibi scanning. When scintigraphy and neck ultrasound are negative/ inconclusive, ${ }^{18} \mathrm{~F}$-fluorocholine PET/CT imaging is indicated. Adding a contrast-enhanced arterial CT phase can reduce the risk of false-positive result from reactive lymph nodes.

IMPLICATIONS FOR PATIENT CARE: These optimized radionuclide imaging techniques should be helpful in improving outcomes, allowing precision parathyroid surgery.

\section{REFERENCES}

1. Khan AA, Hanley DA, Rizzoli R, et al. Primary hyperparathyroidism: review and recommendations on evaluation, diagnosis, and management - a Canadian and international consensus. Osteoporos Int. 2017;28:1-19.

2. Walker MD, Silverberg SJ. Primary hyperparathyroidism. Nat Rev Endocrinol. 2018;14:115-125.
3. Bilezikian JP, Bandeira L, Khan A, Cusano NE. Hyperparathyroidism. Lancet. 2018;391:168-178.

4. Zhu CY, Sturgeon C, Yeh MW. Diagnosis and management of primary hyperparathyroidism. JAMA. 2020;323:1186-1187.

5. Barczyński M, Bränström R, Dionigi G, Mihai R. Sporadic multiple parathyroid gland disease: a consensus report of the European Society of Endocrine Surgeons (ESES). Langenbecks Arch Surg. 2015;400:887-905.

6. Wilhelm SM, Wang TS, Ruan DT, et al. The American Association of Endocrine Surgeons guidelines for definitive management of primary hyperparathyroidism. JAMA Surg. 2016;151:959-968.

7. Bergenfelz AO, Hellman P, Harrison B, Sitges-Serra A, Dralle H. Positional statement of the European Society of Endocrine Surgeons (ESES) on modern techniques in pHPT surgery. Langenbecks Arch Surg. 2009;394:761-764.

8. Zafereo M, Yu J, Angelos P, et al. American Head and Neck Society Endocrine Surgery Section update on parathyroid imaging for surgical candidates with primary hyperparathyroidism. Head Neck. 2019;41:2398-2409.

9. Phitayakorn R, McHenry CR. Incidence and location of ectopic abnormal parathyroid glands. Am J Surg. 2006;191:418-423.

10. Roy M, Mazeh H, Chen H, Sippel RS. Incidence and localization of ectopic parathyroid adenomas in previously unexplored patients. World J Surg. 2013;37:102-106.

11. Levin KE, Clark OH. The reasons for failure in parathyroid operations. Arch Surg. 1989;124:911-914.

12. Akerström G, Malmaeus J, Bergstrom R. Surgical anatomy of human parathyroid glands. Surgery. 1984;95:14-21.

13. Thier M, Nordenström E, Bergenfelz A, Almquist M. Presentation and outcomes after surgery for primary hyperparathyroidism during an 18-year period. World $J$ Surg. 2016;40:356-364.

14. Russell CF, Edis AJ. Surgery for primary hyperparathyroidism: experience with 500 consecutive cases and evaluation of the role of surgery in the asymptomatic patient. Br J Surg. 1982;69:244-247.

15. Rothmund M. Clinical dilemma: a parathyroid adenoma cannot be found during neck exploration of a patient with presumed primary hyperparathyroidism - how should this problem be tackled? Br J Surg. 1999;86:725-726.

16. Hindié E, Melliere D, Perlemuter L, Jeanguillaume C, Galle P. Primary hyperparathyroidism: higher success rate of first surgery after preoperative Tc-99m sestamibi-I-123 subtraction scanning. Radiology. 1997;204:221-228.

17. Westerdahl J, Bergenfelz A. Unilateral versus bilateral neck exploration for primary hyperparathyroidism: five-year follow-up of a randomized controlled trial. Ann Surg. 2007;246:976-980.

18. Gauger PG, Agarwal G, England BG, et al. Intraoperative parathyroid hormone monitoring fails to detect double parathyroid adenomas: a 2-institution experience. Surgery. 2001;130:1005-1010.

19. Lee NC, Norton JA. Multiple-gland disease in primary hyperparathyroidism: a function of operative approach? Arch Surg. 2002;137:896-899.

20. Lou I, Balentine C, Clarkson S, Schneider DF, Sippel RS, Chen H. How long should we follow patients after apparently curative parathyroidectomy? Surgery. 2017;161:54-61.

21. Hughes DT, Miller BS, Park PB, Cohen MS, Doherty GM, Gauger PG. Factors in conversion from minimally invasive parathyroidectomy to bilateral parathyroid exploration for primary hyperparathyroidism. Surgery. 2013;154:1428-1434.

22. Ruda JM, Hollenbeak CS, Stack BC Jr. A systematic review of the diagnosis and treatment of primary hyperparathyroidism from 1995 to 2003. Otolaryngol Head Neck Surg. 2005;132:359-372.

23. Kettle AG, O'Doherty MJ. Parathyroid imaging: how good is it and how should it be done? Semin Nucl Med. 2006;36:206-211.

24. Mullan BP. Nuclear medicine imaging of the parathyroid. Otolaryngol Clin North Am. 2004;37:909-939.

25. Hindié E, Ugur O, Fuster D, et al. 2009 EANM parathyroid guidelines. Eur J Nucl Med Mol Imaging. 2009;36:1201-1216.

26. Greenspan BS, Dillehay G, Intenzo C, et al. SNM practice guideline for parathyroid scintigraphy 4.0. J Nucl Med Technol. 2012;40:111-118.

27. Hindié E, Zanotti-Fregonara $\mathrm{P}$, Tabarin $\mathrm{A}$, et al. The role of radionuclide imaging in the surgical management of primary hyperparathyroidism. J Nucl Med. 2015;56:737-744.

28. Caveny SA, Klingensmith WC III, Martin WE, et al. Parathyroid imaging: the importance of dual-radiopharmaceutical simultaneous acquisition with ${ }^{99 \mathrm{~m}} \mathrm{Tc}$-sestamibi and ${ }^{123}$ I. J Nucl Med Technol. 2012;40:104-110.

29. Hindié E, Melliere D, Jeanguillaume C, Perlemuter L, Chehade F, Galle P. Parathyroid imaging using simultaneous double-window recording of technetium- $99 \mathrm{~m}$ sestamibi and iodine-123. J Nucl Med. 1998;39:1100-1105.

30. Klingensmith WC III, Koo PJ, Summerlin A, et al. Parathyroid imaging: the importance of pinhole collimation with both single- and dual-tracer acquisition. $J \mathrm{Nucl}$ Med Technol. 2013;41:99-104. 
31. Wong KK, Fig LM, Gross MD, Dwamena BA. Parathyroid adenoma localization with ${ }^{99 \mathrm{~m}}$ Tc-sestamibi SPECT/CT: a meta-analysis. Nucl Med Commun. 2015;36: 363-375.

32. Bhatt PR, Klingensmith WC III, Bagrosky BM, et al. Parathyroid imaging with simultaneous acquisition of ${ }^{99 \mathrm{~m}} \mathrm{Tc}$-sestamibi and ${ }^{123} \mathrm{I}$ : the relative merits of pinhole collimation and SPECT/CT. J Nucl Med Technol. 2015;43:275-281.

33. Martin D, Rosen IB, Ichise M. Evaluation of single isotope technetium 99Msestamibi in localization efficiency for hyperparathyroidism. Am $J$ Surg. 1996; 172:633-636.

34. Sandqvist P, Nilsson IL, Grybäck P, Sanchez-Crespo A, Sundin A. Multiphase iodine contrast-enhanced SPECT/CT outperforms nonenhanced SPECT/CT for preoperative localization of small parathyroid adenomas. Clin Nucl Med. 2019;44:929-935.

35. Krakauer M, Wieslander B, Myschetzky PS, et al. A prospective comparative study of parathyroid dual-phase scintigraphy, dual-isotope subtraction scintigraphy, 4D-CT, and ultrasonography in primary hyperparathyroidism. Clin Nucl Med. 2016;41:93-100.

36. Hindié E, Melliere D, Jeanguillaume C, Urena P, deLabriolle-Vaylet C, Perlemuter L. Unilateral surgery for primary hyperparathyroidism on the basis of technetium Tc 99m sestamibi and iodine 123 subtraction scanning. Arch Surg. 2000;135:1461-1468.

37. Grant CS, Thompson G, Farley D, van Heerden J. Primary hyperparathyroidism surgical management since the introduction of minimally invasive parathyroidectomy: Mayo Clinic experience. Arch Surg. 2005;140:472-478.

38. Guerin C, Lowery A, Gabriel S, et al. Preoperative imaging for focused parathyroidectomy: making a good strategy even better. Eur $J$ Endocrinol. 2015;172:519-526.

39. Petranović Ovčariček P, Giovanella L, Carrió Gasset I, et al. The EANM practice guidelines for parathyroid imaging Eur J Nucl Med Mol Imaging. April 10, 2021 [Epub ahead of print].

40. Neumann DR, Obuchowski NA, Difilippo FP. Preoperative ${ }^{123} \mathrm{I} /{ }^{99 \mathrm{~m}} \mathrm{Tc}$-sestamibi subtraction SPECT and SPECT/CT in primary hyperparathyroidism. J Nucl Med. 2008;49:2012-2017.

41. Nehs MA, Ruan DT, Gawande AA, Moore FD Jr, Cho NL. Bilateral neck exploration decreases operative time compared to minimally invasive parathyroidectomy in patients with discordant imaging. World J Surg. 2013;37:1614-1617.

42. Chandramohan A, Sathyakumar K, Irodi A, Abraham D, Paul MJ. Causes of discordant or negative ultrasound of parathyroid glands in treatment of naïve patients with primary hyperparathyroidism. Eur J Radiol. 2012;81: 3956-3964.

43. Kluijfhout WP, Vorselaars WM, Vriens MR, Borel Rinkes IH, Valk GD, de Keizer B. Enabling minimal invasive parathyroidectomy for patients with primary hyperparathyroidism using Tc-99m-sestamibi SPECT-CT, ultrasound and first results of ${ }^{18}$ F-fluorocholine PET-CT. Eur J Radiol. 2015;84:1745-1751.

44. Bergenfelz AO, Wallin G, Jansson S, et al. Results of surgery for sporadic primary hyperparathyroidism in patients with preoperatively negative sestamibi scintigraphy and ultrasound. Langenbecks Arch Surg. 2011;396:83-90.

45. Dy BM, Richards ML, Vazquez BJ, Thompson GB, Farley DR, Grant CS. Primary hyperparathyroidism and negative Tc99 sestamibi imaging: to operate or not? Ann Surg Oncol. 2012;19:2272-2278.

46. Kushchayeva YS, Tella SH, Kushchayev SV, Van Nostrand D, Kulkarni K. Comparison of hyperparathyroidism types and utility of dual radiopharmaceutical acquisition with Tc99m sestamibi and ${ }^{123} \mathrm{I}$ for localization of rapid washout parathyroid adenomas. Osteoporos Int. 2019;30:1051-1057.

47. Michaud L, Balogova S, Burgess A, et al. A pilot comparison of ${ }^{18} \mathrm{~F}$-fluorocholine PET/CT, ultrasonography and ${ }^{123} \mathrm{I} /{ }^{99 \mathrm{~m}} \mathrm{Tc}$-sestaMIBI dual-phase dual-isotope scintigraphy in the preoperative localization of hyperfunctioning parathyroid glands in primary or secondary hyperparathyroidism: influence of thyroid anomalies. Medicine (Baltimore). 2015;94:e1701.

48. Kluijfhout WP, Vorselaars WM, van den Berk SA, et al. Fluorine-18 fluorocholine PET-CT localizes hyperparathyroidism in patients with inconclusive conventional imaging: a multicenter study from The Netherlands. Nucl Med Commun. 2016;37:1246-1252.

49. Quak E, Blanchard D, Houdu B, et al. F18-choline PET/CT guided surgery in primary hyperparathyroidism when ultrasound and MIBI SPECT/CT are negative or inconclusive: the APACH1 study. Eur J Nucl Med Mol Imaging. 2018;45:658-666.

50. Huber GF, Hüllner M, Schmid C, et al. Benefit of ${ }^{18}$ F-fluorocholine PET imaging in parathyroid surgery. Eur Radiol. 2018;28:2700-2707.

51. Grimaldi S, Young J, Kamenicky P, et al. Challenging pre-surgical localization of hyperfunctioning parathyroid glands in primary hyperparathyroidism: the added value of ${ }^{18} \mathrm{~F}$-fluorocholine PET/CT. Eur J Nucl Med Mol Imaging. 2018;45:1772-1780.
52. Morland D, Lalire P, Deguelte S, et al. Added value of ${ }^{18} \mathrm{~F}$-fluorocholine positron emission tomography-computed tomography in presurgical localization of hyperfunctioning parathyroid glands after dual tracer subtraction scintigraphy failure: a retrospective study of 47 patients. Medicine (Baltimore). 2020; 99:e18681.

53. Treglia G, Piccardo A, Imperiale A, et al. Diagnostic performance of choline PET for detection of hyperfunctioning parathyroid glands in hyperparathyroidism: a systematic review and meta-analysis. Eur J Nucl Med Mol Imaging. 2019;46:751-765.

54. Boccalatte LA, Higuera F, Gómez NL, et al. Usefulness of ${ }^{18} \mathrm{~F}$-fluorocholine positron emission tomography-computed tomography in locating lesions in hyperparathyroidism: a systematic review. JAMA Otolaryngol Head Neck Surg. 2019;145:743-750.

55. Rep S, Lezaic L, Kocjan T, et al. Optimal scan time for evaluation of parathyroid adenoma with $\left[{ }^{18} \mathrm{~F}\right]$-fluorocholine PET/CT. Radiol Oncol. 2015;49: $327-333$.

56. Imperiale A, Taïeb D, Hindié E. ${ }^{18} \mathrm{~F}$-fluorocholine PET/CT as a second line nuclear imaging technique before surgery for primary hyperparathyroidism. Eur $\mathrm{J} \mathrm{Nucl}$ Med Mol Imaging. 2018;45:654-657.

57. Noltes ME, Coester AM, van der Horst-Schrivers ANA, et al. Localization of parathyroid adenomas using ${ }^{11} \mathrm{C}$-methionine PET after prior inconclusive imaging. Langenbecks Arch Surg. 2017;402:1109-1117.

58. Mathey C, Keyzer C, Van Simaeys G, et al. Comparison of ${ }^{18}$ F-fluorocholine PET$\mathrm{CT}$ to ${ }^{11} \mathrm{C}$-methionine PET-CT for the localisation of hyperfunctioning parathyroid tissue in primary hyperparathyroidism. Eur J Nucl Med Mol Imaging. 2019;46(suppl 1):S52.

59. Day KM, Elsayed M, Beland MD, Monchik JM. The utility of 4-dimensional computed tomography for preoperative localization of primary hyperparathyroidism in patients not localized by sestamibi or ultrasonography. Surgery. 2015;157:534-539.

60. Sho S, Yuen AD, Yeh MW, Livhits MJ, Sepahdari AR. Factors associated with discordance between preoperative parathyroid 4-dimensional computed tomographic scans and intraoperative findings during parathyroidectomy. JAMA Surg. 2017; 152:1141-1147.

61. Kluijfhout WP, Pasternak JD, Gosnell JE, et al. ${ }^{18} \mathrm{~F}$ fluorocholine PET/MR imaging in patients with primary hyperparathyroidism and inconclusive conventional imaging: a prospective pilot study. Radiology. 2017;284:460-467.

62. Hope TA, Graves CE, Calais J, et al. Accuracy of ${ }^{18} \mathrm{~F}$-fluorocholine PET for the detection of parathyroid adenomas: prospective single center study. J Nucl Med. March 5, 2021 [Epub ahead of print].

63. Piccardo A, Trimboli P, Rutigliani M, et al. Additional value of integrated ${ }^{18} \mathrm{~F}$-choline PET/4D contrast-enhanced CT in the localization of hyperfunctioning parathyroid glands and correlation with molecular profile. Eur J Nucl Med Mol Imaging. 2019;46:766-775.

64. Pretet V, Rotania M, Helali M, Ignat M, Vix M, Imperiale A. ${ }^{18}$ F-fluorocholine PET and multiphase CT integrated in dual modality PET/4D-CT for preoperative evaluation of primary hyperparathyroidism. J Clin Med. 2020;9:E2005.

65. Christakis I, Khan S, Sadler GP, Gleeson FV, Bradley KM, Mihai R. ${ }^{18}$ Fluorocholine PET/CT scanning with arterial phase-enhanced CT is useful for persistent/ recurrent primary hyperparathyroidism: first UK case series results. Ann $R$ Coll Surg Engl. 2019;101:501-507.

66. Orevi M, Freedman N, Mishani E, Bocher M, Jacobson O, Krausz Y. Localization of parathyroid adenoma by ${ }^{11} \mathrm{C}$-choline PET/CT: preliminary results. Clin Nucl Med. 2014;39:1033-1038.

67. Thanseer N, Bhadada SK, Sood A, et al. Comparative effectiveness of ultrasonography, ${ }^{99 \mathrm{~m}} \mathrm{Tc}$-sestamibi, and ${ }^{18} \mathrm{~F}$-fluorocholine PET/CT in detecting parathyroid adenomas in patients with primary hyperparathyroidism. Clin Nucl Med. 2017;42:e491-e497.

68. Beheshti M, Hehenwarter L, Paymani Z, et al. ${ }^{18} \mathrm{~F}$-fluorocholine PET/CT in the assessment of primary hyperparathyroidism compared with ${ }^{99 \mathrm{~m}} \mathrm{Tc}-\mathrm{MIBI}$ or ${ }^{99 \mathrm{~m}} \mathrm{Tc}$ tetrofosmin SPECT/CT: a prospective dual-centre study in 100 patients. Eur J Nucl Med Mol Imaging. 2018;45:1762-1771.

69. Ismail A, Christensen JW, Krakauer M, et al. ${ }^{11} \mathrm{C}$-choline PET/CT vs. ${ }^{99 \mathrm{~m}} \mathrm{Tc}-$ $\mathrm{MIBI} /{ }^{123}$ iodide subtraction SPECT/CT for preoperative detection of abnormal parathyroid glands in primary hyperparathyroidism: a prospective, single-centre clinical trial in 60 patients. Diagnostics (Basel). 2020;10:975.

70. Cuderman A, Senica K, Rep S, et al. ${ }^{18} \mathrm{~F}$-fluorocholine PET/CT in primary hyperparathyroidism: superior diagnostic performance to conventional scintigraphic imaging for localization of hyperfunctioning parathyroid glands. $\mathrm{J} \mathrm{Nucl} \mathrm{Med}$. 2020;61:577-583.

71. López-Mora DA, Sizova M, Estorch M, et al. Superior performance of ${ }^{18} \mathrm{~F}$-fluorocholine digital PET/CT in the detection of parathyroid adenomas. Eur J Nucl Med Mol Imaging. 2020;47:572-578. 
72. Stack BC Jr, Tolley NS, Bartel TB, et al. AHNS series: do you know your guidelines? Optimizing outcomes in reoperative parathyroid surgery: definitive multidisciplinary joint consensus guidelines of the American Head and Neck Society and the British Association of Endocrine and Thyroid Surgeons. Head Neck. 2018;40:1617-1629.

73. Schalin-Jäntti C, Ryhanen E, Heiskanen I, et al. Planar scintigraphy with ${ }^{123} \mathrm{I} /{ }^{99 \mathrm{~m}} \mathrm{Tc}$-sestamibi, ${ }^{99 \mathrm{~m}} \mathrm{Tc}$-sestamibi SPECT/CT, ${ }^{11} \mathrm{C}$-methionine PET/CT, or selective venous sampling before reoperation of primary hyperparathyroidism? $J$ Nucl Med. 2013;54:739-747.

74. Richards ML, Thompson GB, Farley DR, Grant CS. Reoperative parathyroidectomy in 228 patients during the era of minimal-access surgery and intraoperative parathyroid hormone monitoring. Am J Surg. 2008;196:937-942.
75. Hindié E, Zanotti-Fregonara P, Just PA, et al. Parathyroid scintigraphy findings in chronic kidney disease patients with recurrent hyperparathyroidism. Eur J Nucl Med Mol Imaging. 2010;37:623-634.

76. Amadou C, Bera G, Ezziane M, et al. ${ }^{18}$ F-fluorocholine PET/CT and parathyroid 4D computed tomography for primary hyperparathyroidism: the challenge of reoperative patients. World J Surg. 2019;43:1232-1242.

77. Traub-Weidinger T, Mayerhoefer ME, Koperek O, et al. ${ }^{11} \mathrm{C}$-methionine PET/CT imaging of ${ }^{99 \mathrm{~m}} \mathrm{Tc}-\mathrm{MIBI}-\mathrm{SPECT} / \mathrm{CT}$-negative patients with primary hyperparathyroidism and previous neck surgery. J Clin Endocrinol Metab. 2014;99:4199-4205.

78. Habibollahi P, Shin B, Shamchi SP, Wachtel H, Fraker DL, Trerotola SO. Elevenyear retrospective report of super-selective venous sampling for the evaluation of recurrent or persistent hyperparathyroidism in 32 patients. Cardiovasc Intervent Radiol. 2018;41:63-72. 